\title{
Itinerarios escolares y procesos políticos de cuatro mujeres indígenas nasa y kankuamo
}

YESHICA SERRANO RiOBÓ*

Artículo recibido: 16 de diciembre de 2013

Artículo aprobado: 4 de marzo de 2014

Doi: dx.doi.org/10.12804/desafios26.1.2014.05

Para citar este artículo: Serrano Riobó, Y. (2014). Itinerarios escolares y procesos políticos de cuatro mujeres indígenas nasa y kankuamo. Desafíos, 26 (1), 171-198. doi: dx.doi. org/10.12804/desafios26.1.2014.05

\section{Resumen}

Este articulo presenta cuatro trayectorias escolares de mujeres indigenas que incursionaron desde distintos escenarios a algunos campos políticos en donde fueron reconocidas como lideresas de ciertos procesos politicos. En sus experiencias personales se evidencian hechos de violencia simbólica, discriminación racialy de género, pero también emerge la búsqueda de alternativas para cambiar su condición politico-social a partir del acceso a ciertos capitales escolares.

Palabras clave: educación, mujeres indígenas, procesos políticos y organizativos

\footnotetext{
* Magíster en Estudios Políticos e Internacionales y doctoranda en Derecho de la Universidad del Rosario. Estuvo vinculada como joven investigadora al Observatorio de Redes y Acción Colectiva de las facultades de Ciencia Política y Gobierno, y de Relaciones Internacionales de la Universidad del Rosario. Correo electrónico: yekaseri@gmail.com
} 


\title{
School Trajectory and the Political Processes of Four Nasa and Kankuamo Indigenous Women
}

\begin{abstract}
This article discusses four school trajectories of indigenous women who entered from different scenarios into multiple political and organizational processes. Eventually, they were recognized as leaders of political processes involving indigenous women in Colombia. Aspart of theirpersonal experiences, symbolic cases of violence, racial and gender discrimination, but also the search for alternatives in order to change their socio -political conditions are highlighted, as well as, to their access to certain types of schools.
\end{abstract}

Key words: Education, indigenous women, political and organizational processes

\section{Itinerários escolares e processos políticos de quatro mulheres indígenas Nasa e Kankuamo}

\begin{abstract}
Resumo
Este artigo apresenta quatro trajetórias escolares de mulheres indígenas que incursionaram desde distintos cenários, a alguns campos políticos nos quais foram reconbecidas como líderes de alguns processos políticos. Ao longo de suas experiências pessoais, se faz̧em evidentes muitos casos de violência simbólica, discriminação racial e de gênero, mas também, emerge a busca por encontrar alternativas para mudar sua condição político-social a partir do acesso a alguns capitais escolares.
\end{abstract}

Palavras- chave: Educação, mulheres indigenas, processos politicos e organizativos

Durante la investigación para la Maestría en Estudios Políticos e Internacionales, me propuse comprender los procesos de acción colectiva a partir de algunos casos de mujeres nasas y kankuamas que han participado en distintos procesos políticos dentro y fuera de sus comunidades y que tuvieron cierta representatividad y liderazgo en cada una de las actividades emprendidas. 
Ya que se trataba de un ejercicio comparativo de dos casos muy diferentes, pero que compartían la fuerza política en los procesos de mujeres indígenas en distintos ámbitos (gobernaciones, consejerías y secretarías técnicas, entre otros), debía hacer uso de algunas técnicas etnográficas que permitieran acceder a sus experiencias (Montané y Pessoa, 2013, pp. 32-33), inmersas en contextos propios de sociedades globalizadas (Marcus, 2001). En el año 2012 visité resguardos de los pueblos kankuamo y nasa. De la misma manera, observé algunos espacios de participación política en donde había mujeres indígenas reconocidas desde los resguardos como lideresas, pero también reconocidas como lideresas entre lideresas. Asimismo, hice entrevistas etnográficas a las mujeres que habían sido identificadas por miembros de las comunidades como representativas en estos campos y observé sus modalidades de participación en distintos escenarios organizativos comunitarios, nacionales e internacionales.

En las entrevistas emergió un elemento importante que no había contemplado al momento de la formulación de la propuesta de investigación: la educación.

En esta oportunidad me interesa comprender cómo se han construido las trayectorias escolares de cuatro mujeres indígenas — dos del pueblo kankuamo y dos del pueblo nasa- y dar cuenta, a partir de sus relatos, de cómo el acceso a este capital contribuyó a su acceso a los procesos políticos de los pueblos indígenas a los que pertenecen, así como sus limitaciones, dificultades y oportunidades. Ellas son Rosa Manuela Montero, lideresa del pueblo kankuamo y exgerente de Asoarka; Mildred Patricia Montero, ${ }^{1}$ coordinadora del Área de Derechos Humanos de la OIK; Beatriz Saniceto, exgobernadora del resguardo de Avirama del pueblo nasa y Abigail Piñacué, estudiante nasa de la Universidad Autónoma Indígena e Intercultural (Uaiin).

\footnotetext{
1 Murió en el año 2013 en un accidente de carretera. Algunas personas del pueblo kankuamo consideran que no fue un accidente, pues ella era la persona encargada de la formulación de los planes de salvaguarda del pueblo kankuamo, labor que desempeñaba en el cargo de coordinadora de Derechos Humanos de la OIK.
} 


\section{La educación como proyecto de dominación}

La educación que se brinda a los pueblos indígenas ha sido parte de un proceso histórico colonial, en el que las instituciones educativas creadas por el Estado o por comunidades religiosas han sido las encargadas de brindar todos los códigos y recursos culturales. Segato (2010), al retomar la obra de Quijano (2000), explica que el proyecto poscolonialista de los Estados latinoamericanos no solo ocupa el debate de "clases" de sociedades modernas industrializadas. En estos Estados se intersectan múltiples categorías de subordinación como raza, etnia, género y clase, entre otros factores que indican su posición social e histórica (Segato, 2010, pp. 27-30). Tanto la Iglesia como la escuela son las instituciones que cumplen el rol de enseñar y reproducir una ideología sobre la sociedad blanca dominante y los grupos étnicos racializados (indígenas y negros), en condición de estudiantes, para ser asimilados en una sociedad moderna, capitalista, racista y excluyente y así mantener este mismo modelo político y social (Segato, 2010, pp. 32-33). En este sentido, la institución escolar es un instrumento de dominación y jerarquización social, que estratifica la clase social, la raza, el sexo, etc. (Bourdieu, 1997).

Aunque las mujeres entrevistadas consideraron que la educación fue uno de los elementos que les brindó las herramientas cognitivas para escalar en los escenarios políticos de sus pueblos, autores como Bourdieu y Passeron (2001) afirman que la educación es el mecanismo mediante el cual se busca mantener la estructura de poder patriarcal, europeo y racista a partir de la reproducción de significados, valores y prácticas sociales que han sido naturalizadas para responder a los intereses dominantes. En este sentido, la institución escolar es un mecanismo que garantiza "la distribución del capital cultural y, con ello, la estructura del espacio social” (Bourdieu, 1997, p. 33), es decir, la educación es la forma de perpetuar o transformar el orden jerárquico social en el que los sujetos mantienen una relación de podersubordinación, dominante-dominados (Bourdieu, 1997, p. 35; Pinto, 2002, p. 64).

Pratt-Clarke (2013) considera que el acceso escolar permite a las mujeres activistas deconstruir las narrativas y explorar los roles de poder 
a partir de experiencias individuales, así como comprender la intersección de identidades en las vidas de estas mujeres, como género, raza y estatus social. Beatriz, Rosa y Mildred consideran que, desde su vivencia personal, accedieron a algunos espacios políticos locales y de interlocución con el Estado y organizaciones internacionales, con ciertos conocimientos adquiridos durante su formación escolar básica y universitaria. Por el contrario, Abigail considera que la educación no indígena es racista y excluyente, por lo que toma la alternativa de la formación universitaria en la Uaiin en el programa de Pedagogía Intercultural, institución creada por el Consejo Regional Indígena del Cauca (CRIC). Aunque Abigail toma un camino disímil, las cuatro mujeres tienen en común que, a partir de la educación, buscan mejorar su estatus social como mujeres indígenas, es decir, ser respetadas, valoradas, tener espacios de organización y participación, reconocimiento político y social, legitimidad en los procesos políticos y de toma de decisiones. De forma inconsciente, se reproducen lógicas de exclusión y dominación frente a otras mujeres indígenas que no han logrado acceder a los mismos capitales escolares, pues de eso también se trata tener liderazgo y poder político.

Entonces, al tener en cuenta la anterior aproximación sobre la concepción de la educación y entender que el capital escolar es un recurso adquirido, heredado o limitado y negado para muchos (Montané y Pessoa, 2013, p. 8), se aprecia que los modelos de educación bajo los cuales fueron preparadas estas lideresas condicionan las formas del acceso, las dificultades y las limitaciones en el campo político, este último definido como un "microcosmos", parte del espacio social (Bourdieu, 1997, p. 34; 2001, p. 10). Así, las escuelas, la universidad y los institutos son vehículos que "contribuyen (insisto sobre este término) a reproducir la distribución del capital cultural y, con ello, la estructura del espacio social [...] mantiene el orden preexistente, es decir la separación entre los alumnos dotados de cantidades desiguales de capital cultural"' (1997, p. 35).

\section{Educación, género y participación política}

Algunos trabajos como el de Lumby y Coleman (2007) y Pratt-Clarke (2013) explican cómo, mediante el acceso a ciertos recursos escolares, 
las activistas deconstruyen formas tradicionales de poder masculino. Asimismo, han construido metodologías transdisciplinares para abordar — desde la intersección de categorías como raza, género y clase- la comprensión de las múltiples formas de exclusión, así como la construcción de diversos liderazgos de mujeres indígenas.

Las cuatro mujeres a quienes me referiré han formado parte de distintas modalidades educativas y por lo mismo tienen distintos grados de capitales culturales incorporados mediante la imposición de valores, símbolos y prácticas sociales propias de las instituciones escolares de comunidades religiosas y estatales no indígenas. Dos de ellas cursaron estudios de formación profesional, lo que les permitió incorporarse en un campo laboral particular. También han participado en talleres, cursos y diplomados en contextos locales, nacionales e internacionales patrocinados por organizaciones solidarias con las problemáticas de los pueblos indígenas (Kervran, 2010, p. 33), para la formación en liderazgo político y derechos humanos de mujeres indígenas. Esto les ha brindado mayores recursos escolares, legitimados por medio de organizaciones, para adquirir oportunidades políticas que les facilite el acceso a espacios de participación (Tarrow, 2004).

No obstante, estos caminos están llenos de obstáculos. Las mujeres son afectadas física, psicológica, histórica y simbólicamente. $\mathrm{Al}$ respeto, Pratt-Clarke (2013) afirma que, en el caso de las mujeres afroamericanas, deben emprenderse múltiples caminos en sus procesos escolares y políticos, donde son marginadas y excluidas. Esto no parece alejarse de las realidades escolares y políticas de las cuatro lideresas indígenas que menciono en este artículo, pues son evidentes los cambios y las transformaciones que se ven obligadas a realizar para ingresar al campo político.

El primero de estos casos es el de Rosa Manuela Montero, una mujer de 35 años de edad, originaria de la comunidad de Chemesquemena, parte del resguardo kankuamo en el departamento del Cesar. Es madre de dos niños y está casada con el cabildo gobernador del pueblo kankuamo, Jaime Enrique Arias. Su llegada a Valledupar está cargada de violencia simbólica (Encrevé y Lagrave, 2005), en especial, por 
las formas de discriminación y exclusión racial y de género, debido a la condición de inferioridad impuesta en la que se encontraban las mujeres de su familia — limitadas al acceso político y escolar- y a la pobreza y la precariedad cotidianas de las comunidades antes del proceso de reetnización.

El caso de Mildred Montero expresa las problemáticas de una violencia simbólica y estructural, generada por la discriminación racial y de género y el conflicto armado que dificultó su proceso continuo de formación escolar y universitaria. Esta lideresa narra cómo logró estudiar, siempre vinculada al proceso organizativo del pueblo kankuamo.

El 10 de julio de 2013, la prensa local El Pilón informó que Mildred Patricia había fallecido tras sufrir un accidente de carretera. Durante su paso por la OIK, se destacó como una de las lideresas más importantes en temas de mujeres y derechos humanos del pueblo kankuamo.

En el escenario nasa se encuentran los casos de Beatriz Saniceto y Abigail Piñacué. Beatriz, exgobernadora del resguardo de Avirama, expresa las dificultades para acceder a la formación escolar básica y que solo a partir de su trabajo como empleada doméstica pudo empeñarse en superar estas limitaciones y obtener su título de bachiller. Su experiencia individual le permitió incorporarse en los procesos organizativos de los pueblos indígenas de Colombia y en particular del Cauca.

Por otro lado, Abigail Piñacué enuncia cada una de las dificultades para acceder, como mujer indígena, a una formación básica escolar en instituciones estatales y religiosas. Ella expresa que estas instituciones dudaron de su capacidad intelectual a partir de su condición étnica, racial, social y de género, por lo que limitaron sus posibilidades para incorporarse en cualquier sistema educativo no indígena. Por lo mismo, encuentra en el programa que cursa una oportunidad política de cambio para los pueblos indígenas y piensa su formación profesional al lado de su familia con el propósito de rearmonizar las fuerzas espirituales para que el hombre y la mujer sean un complemento indispensable para la vida. 
Puesto que las cuatro mujeres presentan dinámicas muy distintas por su localización geográfica, movilización política y escolar y sus circunstancias históricas y sociales, entre otros factores, su acceso al capital escolar fue desde múltiples espacios; por tal razón, he considerado la recopilación de datos a partir del estudio etnográfico multisituado (Marcus, 2001). Seguir sus procesos e historias significó un reto para comprender su ingreso al capital escolar y a los espacios de participación política.

\section{Rosa Manuela Montero: volver a ser kankuama desde la universidad}

El proceso de reetnización de Rosa Manuela Montero inició durante su vinculación como estudiante a la Universidad Popular del Cesar. Es oriunda de Chemesquemena. Se casó con el cabildo gobernador del pueblo kankuamo, Jaime Enrique Arias, quien la ha apoyado en el proceso organizativo que adelanta con las mujeres artesanas en la Asociación de Artesanas Kankuamas (Asoarka) y la Organización de Mujeres Indígenas Kankuamas (OMIK). Tiene dos hijos, un niño de 9 años y una niña de 2 años.

Durante su infancia, Rosa Manuela se fue a vivir con una tía a la ciudad de Valledupar, pues su madre (que había enviudado cuando ella aún era pequeña) no contaba con recursos económicos suficientes para brindarles educación y una buena calidad de vida, que les permitiera "superarse, para que no nos sucediera igual que a ella, que no tuvo la oportunidad de ir al colegio". Para entonces, Rosa tenía 8 años y no se reconocía como indígena. Entre las cosas que más le molestaron durante este período era que la llamaran "india", porque esta expresión ha sido usada como una calificación negativa para referirse a una conducta y una fisonomía.

El pueblo kankuamo pasó por un trágico proceso de incorporación a la sociedad "civilizada" mediante proyectos escolares y religiosos, lo que trajo como consecuencia una sociedad híbrida en la que no era completamente blanco, para ser como la élite vallenata, pero tampoco indígena, para ser aceptado como tal entre los pueblos que habitan la Sierra Nevada de Santa Marta. Solo a partir de la década del noventa las 
autoridades tradicionales y los miembros de la comunidad comenzaron a llevar a cabo procesos de reapropiación territorial cultural y en 1993 tuvieron el reconocimiento estatal como pueblo indígena (Morales y Pumarejo, 2003; Morales, 2011). Sin embargo, como Rosa Manuela, muchos otros no se distinguían como parte de él.

Parte de su importante cambio, así como la construcción de una identidad como mujer con pertenencia étnica, inició en el proceso de selección de estudiantes becarios por la Organización Indígena Kankuama (OIK), para estudiar varias de las carreras que ofrecía la Universidad Popular del Cesar. Rosa encontró una oportunidad en este espacio. La modalidad de selección de los estudiantes beneficiarios fue mediante una prueba de conocimientos, para legitimar su pertenencia al pueblo kankuamo.

Yo comienzo a leer mucho, luego me fui a la comunidad para empaparme de toda la dinámica del proceso organizativo de la OIK y saber muy bien en qué estaban y qué estaban haciendo [...]. Eso me ayudó mucho para comprender qué es ser indígena kankuamo. La prueba tenía preguntas como: ¿Usted es indígena kankuamo? ¿Por qué cree que es indígena? Eran como ese tipo de preguntas. Entonces, mis respuestas eran que yo sí me identificaba como indígena y mis apuestas estaban en apoyar el proceso para nuestra recuperación cultural, pues nunca era tarde para volver a lo propio; esas fueron mis respuestas (Rosa Manuela Montero, comunicación personal, 21 de marzo de 2012, Valledupar).

Ingresó al programa de Contaduría, pues egresó de un colegio que tenía énfasis en bachillerato comercial. En Colombia existe un mecanismo nacional para validar y legitimar las capacidades de los aspirantes universitarios, mediante una prueba de conocimientos realizada por el Instituto Colombiano para la Evaluación de la Educación (Icfes). Carecer de un puntaje adecuado limita las posibilidades de acceder a la formación profesional. Este proceso tuvo que ser superado por Rosa, aun cuando no tuvo los mejores resultados. No obstante, continuó con su formación profesional. 
En la universidad, Rosa se unió a un grupo de estudiantes kankuamos, con quienes programó actividades culturales para el fortalecimiento de sus tradiciones como la danza, la música, los tejidos de hamacas y mochilas y la preparación de comidas tradicionales. Aunque a partir de ese momento comenzó a vincularse con el proceso de reetnización de su pueblo, reconoce que el período de adaptación a la institución universitaria fue difícil. Rosa adquirió cierta experiencia como administradora de una tienda de artesanías en el año 2004. Sin embargo, la actividad comercial durante este período fue afectada por la violencia ${ }^{2}$ que se vivía en los territorios, ya que no había manera de llevar materias primas y traer los productos de las mujeres artesanas. En el año 2005 fue nombrada como gerente de Asoarka, un espacio autónomo de la OIK, en donde las mujeres hacían actividades para el fortalecimiento de los tejidos tradicionales y la comercialización de sus productos.

Su experiencia en el trabajo de base con mujeres indígenas le permitió participar en la primera Cumbre Continental de Mujeres Indígenas, realizada en Puno (Perú) en 2008. Contó con el apoyo importante de su esposo y de la Organización Nacional Indígena de Colombia (ONIC).

Gracias a que tuve el apoyo de mi esposo Jaime, él me apoyó con las millas de vuelo para el pasaje de Bogotá a Lima para poder tener esa experiencia con esas mujeres, salir del país y conocer. De Lima a Puno me apoyó la ONIC; no me apoyaron completamente porque yo no tenía una trayectoria de trabajo con mujeres y mi proceso era local con las mujeres artesanas (Rosa Manuela Montero, comunicación personal, 21 de marzo de 2012, Valledupar).

Santamaría (2013) explica que las mujeres pueden verse excluidas de muchos espacios de participación. No obstante, Rosa Manuela da un

\footnotetext{
2 Sobre la violencia acontecida entre los años 1985 y 2008, se encuentra el trabajo realizado por la Organización Indígena Kankuama (2009), en el cual se relata el proceso de desaparición forzada durante este período y sus víctimas. También puede verse el informe sobre la violencia en la Sierra Nevada de Santa Marta titulado "Cuando la madre Tierra llora. Crisis en derechos en humanos y humanitarios en la Sierra Nevada de Gonawindúa (Santa Marta)", en el que se hace un diagnóstico de la violación de derechos humanos de los pueblos de la Sierra Nevada de Santa Marta y, entre estos, el pueblo kankuamo.
} 
salto a este campo a partir de lo que Santamaría, al retomar las palabras de Gilligan y Noddings, define como "ética del cuidado", por medio de la cual se han presentado rupturas en los modelos políticos masculinos.

A pesar de lo difícil que fue esta experiencia para Rosa Manuela, por sus temores y angustias durante su primer viaje, ella identifica esta Cumbre como uno de los momentos más importantes de su vida, pues fue ahí donde reafirmó su condición étnica y de género. Su interés por los procesos organizativos de las mujeres la llevó a encontrarse con la experiencia de las Bartolinas Sisas ${ }^{3}$ de Bolivia y a pensar los procesos organizativos con las mujeres kankuamas. Un año después, Rosa comenzó a tejer redes de apoyo entre la Asociación de Artesanas Kankuamas (Asoarka) y la OMIK, coordinada por Delviz Estrada, para gestionar apoyos de organizaciones de cooperación internacional solidarias con las problemáticas indígenas como el Consejo Noruego (Kervran, 2010), con el fin de desarrollar talleres en el marco de la Escuela de Lideresas del Pueblo Kankuamo.

Esta iniciativa tomó forma en el año 2010, durante el diplomado internacional para mujeres indígenas lideresas, en el que participó Rosa Manuela como becaria de este programa porque tenía el perfil exigido en la convocatoria: mujer indígena profesional con experiencia en trabajo de base. Si bien Rosa ya no vivía en las comunidades, mantenía un estrecho lazo con las mujeres por medio de Asoarka y la OMIK. Este diplomado, financiado por el Fondo Indígena Internacional, exigía la socialización de cada uno de los conocimientos brindados durante el curso en las bases comunitarias. Fue así como Asoarka y la OMIK, con la coordinación de Rosa Manuela, construyeron redes de

\footnotetext{
3 Conocida como la Confederación de Mujeres Campesinas Indígenas Oriundas de Bolivia "Bartolina Sisa" (CNMCIOB "BS"), emerge durante la dictadura en la década del setenta como una forma de resistencia, mediante la conformación de sindicatos de mujeres indígenas campesinas. Solo en el año 1980 se realizó el primer congreso nacional de la Federación de Mujeres Campesinas Indígenas Oriundas de Bolivia "Bartolina Sisa". Estas mujeres toman su nombre en honor a la heroína aimara que luchó en contra de los atropellos durante el período colonial.

4 Mujer de 40 años aproximadamente. Es una importante lideresa de la OMIK y ha sido delegada por la OIK como coordinadora en temas de mujer en el pueblo kankuamo.
} 
Fotografía 1. Encuentro de mujeres de la OMIK en la comunidad de Atánquez, mayo de 2012

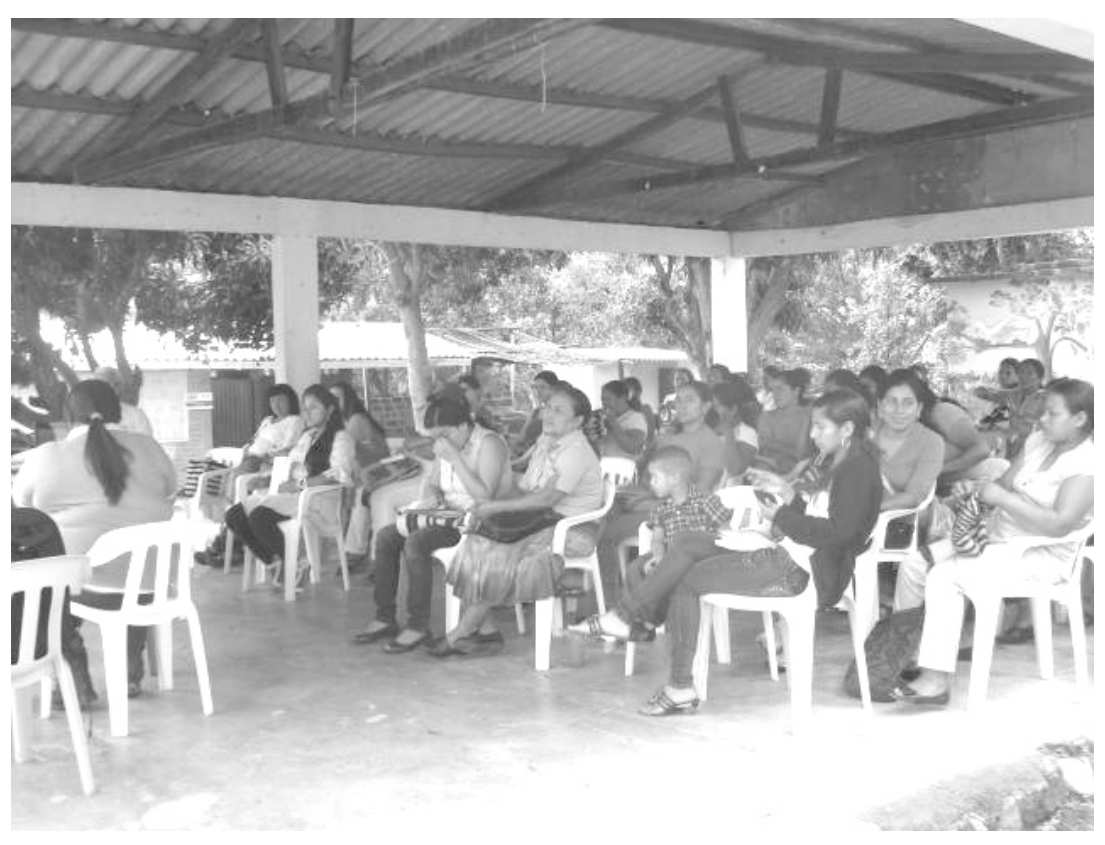

Fuente: Yeshica Serrano Riobó.

apoyo local y transnacional con el Consejo Noruego, la Escuela de Formación Indígena (EFIN) y la ONIC para el desarrollo de la Escuela de Lideresas Kankuamas (Keck y Sikkin, 2001), de la cual ya se han graduado más de 150 mujeres de este pueblo. La experiencia es vista por Rosa como una oportunidad de acceso y manejo del discurso político (Pratt-Clarke, 2013).

\section{Beatriz Saniceto: servicio doméstico y escolarización}

Contrario al caso expuesto surge la experiencia de Beatriz Saniceto. Ella nació en la vereda San Miguel del municipio de Páez, en el departamento del Cauca. Afirmó que no tenía certeza sobre su fecha real de nacimiento, pues en algunos documentos aparecía registrada con fecha de nacimiento del 23 de junio de 1971 y otro en el año 1964. Asimismo, sus nombres fueron cambiados. En un registro de naci- 
miento figura como Beatriz Aniceto y en el otro como Beatriz Saniceto. Ella prefiere que para la entrevista dejemos la segunda opción: María Beatriz Saniceto. Está separada de su último esposo a causa de la violencia intrafamiliar. Tiene cuatro hijos, uno de 15 años, otro de 12 , el siguiente de 10 años y el último de 2 años y dice que aguantaría cuatro más.

Beatriz inició su vida escolar a los 10 años de edad. Menciona que para esa época no era indispensable llevar a las niñas a los colegios. Se prefería tener en mente varios candidatos para ser los esposos de las niñas y que pudieran sostenerlas. Sin embargo, sus padres accedieron a que cursara Primero de primaria. Aquí cabe resaltar otras formas de exclusión y discriminación de género, manifestadas en sus familias y sus pueblos de origen. Mediante prácticas y creencias colectivamente establecidas, en estas sociedades también se imponen restricciones arbitrarias al acceso político de mujeres indígenas. Por lo mismo, Beatriz Saniceto buscó alternativas que le permitieran superar estas condiciones de exclusión familiar y social y escapó de su casa para ir a trabajar como empleada de servicio doméstico de una señora de Bogotá, cuando aún no superaba los 12 años de edad.

Yo siempre renegaba de que ahí, donde estaban esos filos, ${ }^{5}$ siempre debieron existir otras cosas más allá, porque en ese tiempo no había ni televisión, nadie conocía nada afuera. Y yo mantenía en la mente que afuera había otras cosas. Entonces yo decidí escaparme una vez de la casa y me fui. Me escapé con una señora que me dijo que me fuera para Bogotá (Beatriz Saniceto, comunicación personal, 16 de febrero de 2012, resguardo de Avirama).

La migración de las mujeres indígenas a las grandes ciudades ha sido investigada por Ángela María Gil Roldán. Ella explica que muchos de los procesos migratorios de las mujeres indígenas son generados por la búsqueda de mejores condiciones laborales y escolares (Gil, 2005, pp. 32-33). Beatriz puso como condición de trabajo que le permitan

\footnotetext{
5 Como "filos" se refiere a las partes más altas de las montañas que rodean el territorio del resguardo indígena donde habitaba.
} 
estudiar, pero una vez instalada en su nuevo trabajo, los compromisos y acuerdos previos desaparecieron.

Debido a los malos tratos recibidos por parte de la dueña de la casa, Beatriz resolvió cambiar de trabajo y se fue a otra casa de familia. Allí le permitieron estudiar Segundo y Tercero de primaria, pero volvió a recibir maltratos físicos. Cambió de casa una vez más y, aunque en esta última recibió buenos tratos, no pudo estudiar. Entonces, resolvió que lo mejor era regresar al resguardo para buscar sus documentos y volver a la escuela. En esa oportunidad pidió el apoyo de su familia, pero le fue negado, así que se presentó en un colegio de monjas que había en el resguardo de Calderas y en la Normal de Tierradentro; fue rechazada en ambas partes. Bourgois (1996) explica que parte de construir una sociedad socialmente excluyente y racista pasa por la escuela, lugar donde se reproducen los códigos, valores y modelos sociales que debemos seguir (Bourgois, 1996, p. 176). La escuela puede ser impositiva, dominante y excluyente y dificultar el acceso de capital escolar de aquellos que se encuentran en la base de la jerarquía de subordinación, como en el caso de Beatriz.

Al fin, logró cursar el bachillerado en una institución religiosa en Ibagué, gracias al apoyo que le brindó una monja y terminó en el Conservatorio de Música de Ibagué. Deseaba ser profesional en Zootecnia, pero su examen de Icfes no fue muy bueno, por lo que no ingresó a la universidad. Más adelante llegaron dos de sus hermanas con la intención de estudiar y cambiar sus condiciones de vida, por lo que Beatriz asumió el compromiso de asegurar la educación de sus hermanas. Durante este período se inscribió en el SENA en un curso de Contabilidad.

Ahí entré al SENA a hacer un curso de Contabilidad, pero después me puse a pensar que yo he estado estudiando y estudiando y pensaba que ya era mucho título el de bachiller [se ríe]. Entonces, fue cuando yo dije: "Voy a trabajar para darle estudio a ellos, a mis hermanos y hermanas menores". Eso era como lo que yo había pensado y me puse a trabajar (Entrevista a Beatriz Saniceto, 16 de febrero de 2012. Resguardo de Avirama). 
Sin embargo, un accidente con una de sus hermanas la obligó a regresar al resguardo de Avirama en el año 1992. En su retorno, comenzó a repensar el tema de la identidad como mujer indígena.

La identidad como indígena yo nunca la he perdido. Cuando llegué, presenté lo que había hecho en el colegio en el Tolima y los trabajos y cursos que había realizado. En el colegio yo decía que era indígena. Acá, a partir de la Constitución del 91 pues estábamos en eso, la ONIC coordinaba en Bogotá. Yo conocía porque cuando trabajaba en Ibagué, en el almacén, a veces iba a Bogotá con el mismo patrón, entonces yo salía mucho para allá, para la ONIC. Cuando yo llegué acá, llegué con ideas claras del cabildo (Beatriz Saniceto, comunicación personal, 16 de febrero de 2012, resguardo de Avirama).

A partir de los conocimientos adquiridos tanto en su formación escolar como en las experiencias de viajes y trabajos, Beatriz fue nombrada en 1994 como secretaria del cabildo. Desde ese momento, se convirtió en una activista de la lucha indígena del Cauca y de las problemáticas que aquejaban a las mujeres de su pueblo; pronunció críticas a los poderes organizativos racistas y excluyentes del Estado, a la violencia física, a la subordinación y a la exclusión de las mujeres en los procesos políticos locales de los resguardos de Tierradentro y Avirama.

En las organizaciones locales, los pobladores son los veedores de la labor de cada uno de los funcionarios de los cabildos indígenas. Por la gestión de Beatriz en el resguardo, fue seleccionada como coordinadora del Programa de Mujer, del CRIC, para el diseño y ejecución de talleres de fortalecimiento de prácticas tradicionales como los tejidos de mochilas y tinturas naturales y el rescate de los conocimientos tradicionales. Luego fue nombrada por dos años seguidos, entre 1998 у $1999 .^{6}$

\footnotetext{
6 Vale la pena resaltar que la Gobernación en los cabildos indígenas del Cauca es ocupada por un líder o una lideresa por un período de un año, que no es remunerado económicamente. Durante este lapso, el gobernador recibe apoyo y auxilio de las personas de la comunidad tanto para su sostenimiento personal y familiar.
} 
Ser aceptada en un contexto masculino resulta complicado para muchas mujeres que buscan reconocimiento, respeto y legitimidad en los espacios de participación política. Algunas de ellas deben hablar con mucha más fuerza e incluso asumir maneras masculinas de hablar y actuar. "Y pues bueno, a veces había unos choques, pero yo no me dejaba. A veces los compañeros me hacían unos ataques duros. Pero entonces, en las reuniones grandes, yo respondía igual como los hombres" (Beatriz Saniceto, comunicación personal, 16 de febrero de 2012, resguardo de Avirama).

En 2001 empezó a hacer un diagnóstico de mujeres en Tierradentro, el cual fue apoyado por Ruta Pacífica. ${ }^{7}$ A partir de ahí, se realizaron talleres en la nueva Escuela de Lideresas que, como en el caso de Rosa Manuela, se logró mediante la institución de redes de apoyo solidarias nacionales como Ruta Pacífica y transnacionales como la Agencia Española de Cooperación Internacional para el Desarrollo (Aecid). Entre los años 2005 y 2006 se graduaron alrededor de 150 mujeres.

Yo me fui a España para el taller de gobernabilidad para exponer un caso sobre el pueblo nasa frente al informe del PNUD Callejón sin salida. De eso me quedaron muy buenos puntos. También las fortalezas que nos han quedado, porque la Escuela de la mujer hoy está ahí. Las mujeres ya pronuncian, salen y opinan y, por lo menos, denuncian los maltratos que les hacen a las mujeres tanto por parte del marido como de los grupos que invaden, como el Ejército, la guerrilla, porque ese tema se trabajó mucho sobre todo en la Escuela de Lideresas (Beatriz Saniceto, comunicación personal, 16 de febrero de 2012, resguardo de Avirama).

A raíz de esta experiencia, Beatriz se postuló como una de las candidatas por Colombia al proyecto internacional de Mil mujeres por la paz, en el que participaron alrededor de doce mujeres del país. Aunque

\footnotetext{
7 Movimiento feminista, antimilitarista y pacifista que lucha por la solución del conflicto armado de forma negociada. Busca la reparación integral de las víctimas, en especial, mujeres y la reconstrucción de la memoria histórica y colectiva de los pueblos para garantizar la no repetición.
} 
no recibió el premio, de esta experiencia quedó un libro que narra su proceso. Beatriz destaca que las mujeres están participando como gobernadoras, secretarias de la Gobernación, alguaciles y coordinadoras de programas de la organización indígena, "pues han sabido tomar el bastón de mando". Sin embargo, cree que aún falta avanzar mucho más en los procesos organizativos de las mujeres, porque son ellas las que tienen la disposición del diálogo y, por ende, de la resolución de conflictos. Piensa que, como mujer, tiene un gran compromiso con el territorio, la familia y la organización.

\section{Mildred Patricia Montero: la organización como escuela}

Los procesos migratorios expuestos dan cuenta de situaciones traumáticas y violentas, en las que Rosa y Beatriz salieron de sus lugares de origen para encontrar alternativas escolares que les permitieran mejorar su estatus socioeconómico y superar condiciones de discriminación y exclusión por raza y género.

El caso de Mildred Montero es muy distinto a los anteriores, aunque busca los mismos objetivos por otros canales. Era una mujer de 32 años cuando murió en un trágico accidente de carretera. Su trayectoria escolar inició en la comunidad de La Mina con el apoyo de su mamá, la señora Teodolinda Montero, una mujer muy activa en los procesos organizativos de la Junta de Acción Comunal. A sus 14 años, cuando inició el período de la violencia entre 1998 y 2008, Mildred tuvo que salir de la comunidad de La Mina junto con su madre y sus hermanos.

Cuando llegó la violencia muchas personas se tuvieron que desplazar. Ahí fue cuando la gente pasó trabajo o todavía están pasando trabajos. Tenemos gente por Valledupar, en Bogotá, casi por toda Colombia. Son desplazados por culpa de la violencia. Incluso a mi mamá le tocó irse por eso, por la violencia, porque ella puso una tienda y llegaron, cuando eso, las autodefensas y se llevaron todas las cosas de la tienda. La dejaron sin nada (Mildred Patricia Montero, comunicación personal, 15 de marzo de 2012, comunidad de La Mina). 
Su llegada a Valledupar estuvo llena de dificultades por las pérdidas generadas debidas al saqueo de grupos paramilitares. Su carencia de capital económico se vio reflejada en la falta de alimentos para garantizar dos comidas en el día y los transportes hacia el colegio, por lo que debía caminar casi una hora para llegar a su escuela. Ante esta circunstancia, su madre decidió regresar a la comunidad de La Mina en 2006, cuando Mildred tenía 17 años y había terminado el bachillerato en Valledupar.

Cuando yo salí del bachillerato, yo quería estudiar, pero no tenía el recurso; entonces terminé el bachillerato con mucho esfuerzo. Tampoco había las posibilidades de seguir; incluso hasta ahora es que estoy estudiando. Estoy becada en la UNAD donde estudio Psicología. Voy en quinto semestre. Sin embargo, la escuela mía ha sido la organización, pero es eso, porque no fue porque no quisiera estudiar. Muchas veces, otras personas, como los ricos, no aprovechan las oportunidades y nosotros, que queremos estudiar, no tenemos a veces esas posibilidades (Mildred Patricia Montero, comunicación personal, 15 de marzo de 2012, comunidad de La Mina).

Como bien los expone Pratt-Clarke (2013), los beneficios escolares son repartidos de acuerdo con los intereses dominantes, en los que son beneficiados aquellos con un alto estatus social y pertenecen a la esfera cultural, política y económica más privilegiada. Como expone Tarrow (2004), las oportunidades políticas se presentan cuando se abren algunos canales que permiten la movilización o se reprimen de tal forma que los actores buscan alternativas para movilizarse. Mildred carecía del capital económico y cultural en el contexto de una sociedad dominante, pero se había nutrido desde su infancia con los consejos de su madre, quien le reiteraba su pertenencia étnica kankuama.

Luego de su retorno a la comunidad de La Mina, se encontró con otra ola de violencia. Mildred había decidido casarse con un joven y resolvió quedarse en la comunidad, mientras su madre y sus hermanos regresaron a Valledupar. A partir de ese instante, se interesó por los procesos organizativos alrededor de la creación de la Comisión 
de Derechos Humanos de la OIK, liderado por Fredys Arias, a pesar de los comentarios negativos de algunos hombres por la inclusión de mujeres en este proceso.

El cabildo menor nos informó que iban a conformar la Comisión de Derechos Humanos de la comunidad; de ahí salieron tres compañeros, pero no salió ninguna mujer. Como era voluntario, el que quisiera montarse, entonces yo me levanté y dije que quería participar. Me acuerdo tanto que los hombres, las autoridades, formaron una polémica, hablaban internamente y decían que no se podía, que tenía que ser un hombre. Entonces las mujeres empezamos a hablar desde ese día. Yo les dije que el mismo derecho que tenían los hombres lo teníamos nosotras las mujeres y les íbamos a demostrar que sí podíamos participar (Mildred Patricia Montero, comunicación personal, 15 de marzo de 2012).

Mientras surgía este proceso, Mildred inició su carrera como auxiliar de enfermería. Esto le permitió trabajar por dos años en su comunidad, cuando realizó las prácticas de su formación profesional y así conoció las problemáticas que estaban enfrentando las mujeres de su pueblo. Ingresó a la Comisión de Mujeres de la comunidad de La Mina para brindar apoyo a las mujeres víctimas de la violencia intrafamiliar y del conflicto armado. Aunque Mildred no disponía de los capitales escolares y económicos, sí tenía convicción frente a la pertenencia étnica como kankuama, definida por Santamaría (2008) como "capital étnico".

Llevaba a cabo un proceso interesante como defensora de derechos humanos, madre comunitaria del Instituto Colombiano de Bienestar Familiar (ICBF), enfermera y activista kankuama. En varias oportunidades hubo quejas de algunos hombres que afirmaban que Mildred incitaba a las mujeres a formar parte de los procesos organizativos. Sin embargo, el cabildo gobernador siempre se mostró interesado por los procesos que adelantaban mujeres como Mildred desde distintos frentes los procesos organizativos de las mujeres kankuamas.

Debido a la gestión realizada desde la comunidad, Mildred fue convocada para ser la secretaria del cabildo gobernador. En ese momento 
de su vida laboral, fue invitada por la Escuela de Formación Indígena (EFIN) para un encuentro de mujeres kankuamas. Mildred considera que ese fue uno de los espacios que le permitieron "darse a conocer", con su trayectoria y experiencia de trabajo desde la base del pueblo kankuamo. En el año 2012 fue nombrada como coordinadora de la Comisión de Derechos Humanos de la OIK y de la Comisión Regional de Derechos Humanos de la Macro Norte.

Parte de sus intereses académicos era la Sociología, pero necesitaba un programa académico y una institución que se ajustara a su vida como madre, esposa, trabajadora y activista, por lo que se inscribió en la Universidad Nacional Abierta y a Distancia (UNAD) en el programa de Psicología. Como define Gil, la educación permite que estas mujeres puedan incorporarse en una "comunidad cultural más amplia [...] porque les aporta lo que no tienen y les proporciona contenidos de experiencia que les son ajenos" (Gil, 2005, p. 35).

Finalmente comencé a estudiar Psicología porque uno tiene que superarse como mujer y porque realmente la carrera que yo quería era Sociología, pero no pude estudiar porque tenía que ser presencial. No hay un programa a distancia. Entonces escogí Psicología, porque se me hace más fácil estar allá cada quince días. Por otro lado, a mí me gusta mucho relacionarme con las personas, conocer las situaciones, ayudarles a buscar las soluciones; soy de las que me cargo los problemas de otros, como me dice mi mamá. Yo le he cogido amor a mi carrera, se me ha hecho fácil y aspiro a terminarla (Mildred Patricia Montero, comunicación personal, 14 de abril de 2012, Bogotá). 


\section{Fotografía 2. Encuentro de la Macro Regional Norte, Codazzi, marzo de 2012}

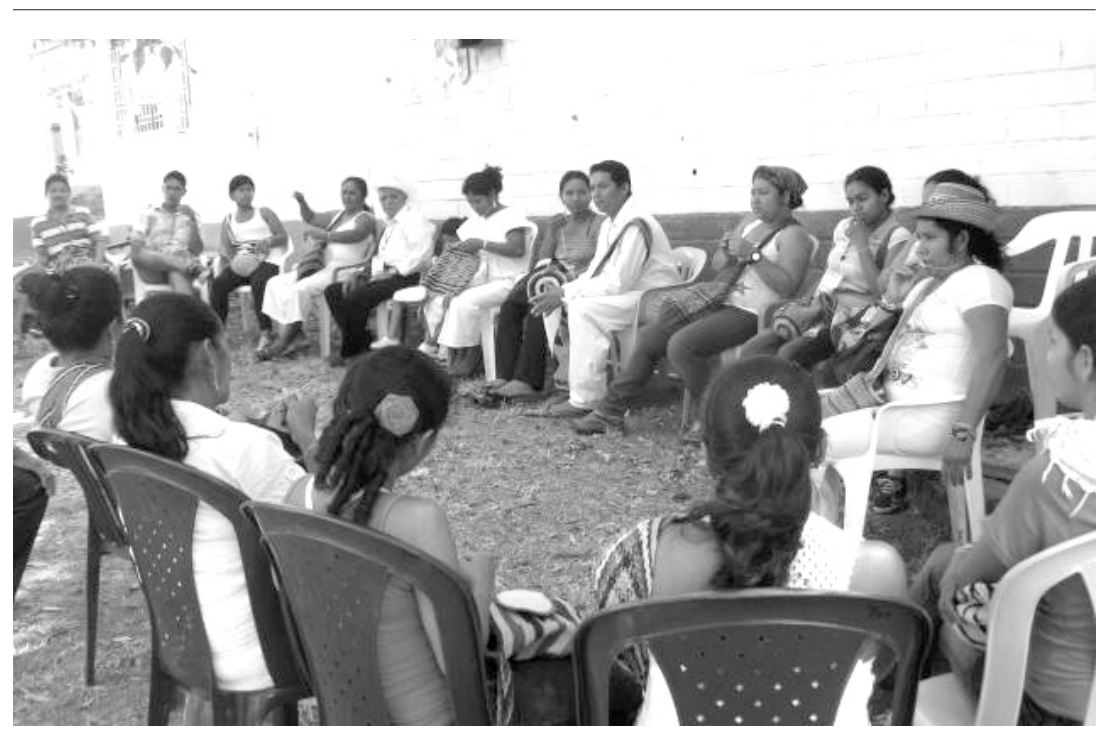

Fuente: Yeshica Serrano Riobó.

\section{Abigail Piñacué: desencuentros escolares frente a oportunidades interculturales}

Es muy probable que las tres mujeres mencionadas no hayan dado cuenta a profundidad de las grandes complejidades y dificultades que representa para una mujer indígena acceder a ciertos capitales escolares. Abigail Piñacué es muy explícita con sus percepciones, sentimientos y frustraciones frente a los desencuentros escolares por su condición sexual, de género y de raza.

Abigail es una mujer de 31 años de edad. Es la cuarta hija entre nueve. Logró terminar la primaria sin muchas novedades; no obstante, cuando ingresó al bachillerato se enfrentó con múltiples dificultades, como la discriminación evidente hacia las mujeres indígenas por parte de los colegios religiosos, el prejuicio de la baja capacidad intelectual de las mujeres indígenas y el bajo estatus académico de las escuelas nocturnas, entre otros. 
Abigail afirma que estudió en muchos lugares. Había iniciado el bachillerato en una escuela nocturna y deseaba continuar sus estudios en la jornada diurna, pero consideraba que las directivas de la última dudaban de las capacidades intelectuales de los estudiantes de la primera, por lo que no fue aceptada. Luego se desplazó hacia el resguardo de Inzá para estudiar en el colegio de esta comunidad, pero también fue rechazada, pues la institución necesitaba mantener cierto prestigio sobre la calidad de los estudiantes admitidos. Intentó nuevamente en Guanacas con la ayuda de uno de sus hermanos, mas la respuesta fue negativa.

Entonces fui a Guanacas con mi hermano, que era chicanero, a un colegio de monjas acá arriba y me dijeron que no. Nos citaron a una reunión de profesores y me dijeron que no estudiara. Yo creo que era más porque era indígena, ¿porqué más sería, pues? Pero principalmente fue una profesora la que me dijo que no, porque ella dudaba que estuviera en las mismas condiciones académicas que los otros. Yo le dije que no y que podía demostrarle que estaba en mejores condiciones, pero su decisión fue un no terminante. Luego me dijo que repitiera y yo no quise (Abigail Piñacué, comunicación personal, 17 de febrero de 2012, resguardo de Segovia).

En 1995 se inscribió en Tierradentro en un colegio que apenas estaba comenzando y necesitaba estudiantes, tal y como ella afirma. Ahí la aceptaron con la condición de repetir noveno. A pesar de terminar el bachillerato, Abigail siente que por ser pobre e indígena se presentaron todas las dificultades para ingresar a una institución educativa no indígena. Expresa su indignación al decir que los estudiantes deberían ser aceptados independientemente de su condición socioeconómica y étnica.

Para pagar sus estudios debía trabajar en el servicio doméstico durante las mañanas y estudiar en las horas de la tarde. En la jornada nocturna asistían hombres no indígenas, quienes asumían su condición étnica y de género como una limitante para ocupar un lugar en ese espacio. No obstante, Abigail consideraba que la mejor manera de defenderse de los hombres en estos espacios de disputa era obtener los mejores resultados académicos para ganar su respeto. Bourgois (1996) propone 
que obtener el respeto implica violar las reglas de segregación racial, de estatus social y de género para ganarse un lugar en la sociedad.

Ser indígena en esa época era muy pesado; claro que ahora no. Por lo menos se ha logrado un cierto grado de respeto. Por ejemplo, en Tierradentro, hay cambios, pues se ha avanzado en la recuperación de tierras, sobre todo desde la minga de San Andrés. Creo que hay que ser bruto para discriminar a un indígena, por lo menos ahora, lo piensan dos veces, porque antes, el grado de discriminación era bastante fuerte (Abigail Piñacué, comunicación personal, 17 de febrero de 2012, resguardo de Segovia).

Aunque Abigail no ha participado como activista de los procesos organizativos de mujeres indígenas en el Cauca, sí ha sido invitada a participar en talleres, charlas y seminarios promovidos desde la Ruta Pacífica de mujeres. A partir de los distintos espacios de información y de formación tanto informal como formal - por ejemplo, la Universidad Autónoma Indígena Intercultural (Uaiin)—, Abigail ha construido una postura crítica sobre el rol de las mujeres indígenas en los procesos políticos y las concepciones de género y feminismo. Para ella, las mujeres siempre han estado muy cerca de los procesos que ha adelantado el movimiento indígena en Colombia, como por ejemplo, en la recuperación de tierras.

Cuestiona los enfoques de género, porque dice que esto llegó de la mano de los programas con enfoque de género promovido por Aecid y no es un concepto incorporado en la lengua nasa yuwe. Postula que estas perspectivas fomentan la discriminación y segregación entre hombres y mujeres. El género es una categoría de análisis que exalta las diferencias entre hombres y mujeres y permite empoderar a la mujer mediante la estigmatización del hombre.

Yo estuve participando en una época con unas psicólogas acá en Inzá, pero siempre enfocan el género hacia el lado de la igualdad de derechos y, de todas maneras, llegan a un extremo; siempre están discriminando. Llegan a un punto que dejan un sabor como de individualismo, cuando dicen que nosotras también tenemos 
derecho. Y cuando les dicen que no tienen que dejarse, el otro, que tiene tanto orgullo, usa el mismo extremo para defenderse (Abigail Piñacué, comunicación personal, 17 de febrero de 2012, resguardo de Segovia).

Desde su perspectiva, el verdadero problema que afecta a hombres y mujeres es que no saben vivir en comunidad. Por lo mismo, plantea que la distinción de roles entre hombres y mujeres es parte de la herencia misógina de la Iglesia católica, de forma que el campo de lucha de las mujeres se encuentra en lo espiritual. Desde su experiencia como secretaria, relatora del cabildo y educadora, considera que ingresar al campo político puede ser un proceso interesante, aunque implica alejarse de los hijos y dejar su educación en manos de otras personas, como también estar en disputa con los hombres por el espacio que ellas podrían ocupar.

Abigail recuerda que, en una reunión de cabildo, los hombres estaban disgustados con los programas de planificación familiar, porque las mujeres ahora solo quieren tener un hijo o dos y, en otros casos, la planificación permite que muchas otras mujeres se vayan a las ciudades a estudiar o a "rebuscar" ingresos para sus familias o para sí mismas. Como consecuencia, para Abigail estas mujeres "se han vuelto mucho más simples", pues ya no quieren tejer, no hablan su lengua y algunas no quieren volver al territorio, lo que ella entiende como una de las consecuencias de los modelos educativos de nuestra sociedad.

En respuesta a los esquemas no indígenas, el CRIC ha establecido como principio de la plataforma política el fortalecimiento de la educación propia. En el marco de este principio, se constituyó la Universidad Autónoma Indígena Intercultural (Uaiin) con el fin de brindar formación profesional a los estudiantes indígenas mediante programas de formación profesional que respondan a las necesidades de los pueblos indígenas del Cauca. Los espacios que brinda la Universidad para el proceso de capacitación son móviles y permiten flexibilizar la presencia de los hijos en los talleres de formación profesional. Por eso, asevera que este modelo educativo se ajusta a las condiciones reales de las mujeres indígenas. 
Yo he criado a mi hijo aquí en Pedagogía, desde cuando era chiquito y luego con ella [se refiere a su hija]. Siempre he andado con ellos, porque esta universidad no les cierra la puerta a los hijos. Entonces uno puede andar con ellos, estar pendiente. Varias mujeres en Pedagogía han estado criando niñitos ahí (Abigail Piñacué, comunicación personal, 17 de febrero de 2014).

La profesionalización de las mujeres, así como su incursión en el ámbito político es muy cuestionada por distintos miembros del pueblo nasa, ya que alegan que las mujeres abandonan a sus hijos, van en busca de "mozos" o se quedan trabajando fuera de las comunidades. Esto desarticula y desarmoniza los procesos organizativos, familiares y espirituales del territorio. Incluso recuerda las críticas que le hacían su madre y su esposo, quienes decían que ella debería dedicarse a los hijos antes de estudiar.

\section{Conclusiones}

Los itinerarios académicos de Rosa, Beatriz, Mildred y Abigail presentan cuatro trayectorias de estas mujeres kankuamas y nasas, que buscan alternativas para superar todas las formas de discriminación racial y de género. Estas cuatro experiencias están llenas de matices y contrastes que muestran la diversidad de posibilidades de acceder a los espacios políticos con unos mínimos o máximos recursos escolares. Estos recursos han significado transformaciones en las condiciones de vida de cada una de ellas; sus experiencias individuales las ubican espacial, social, cultural y políticamente en contextos diferentes, aun cuando todas son activistas indígenas.

Los procesos de estas mujeres forman parte de un nuevo colonialismo disfrazado en el marco jurídico constitucional que defiende la diversidad étnica y cultural de los pueblos indígenas en Colombia. Las posibilidades educativas de las mujeres indígenas son limitadas, puesto que deben adaptarse a las condiciones de subordinación de un sistema escolar no indígena impuesto. Estas instituciones cumplen el papel de mantener el orden preestablecido de las estructuras de poder político y social (Bourdieu, 1997). 
Axel Rojas (2007) afirma que la educación para pueblos indígenas es una ficción creada por el Estado, porque el modelo educativo nacional está orientado a reproducir las estructuras de dominación y exclusión racial (Rojas y Castillo, 2007).

[...] la educación para grupos étnicos se ofrece a los grupos étnicos; es parte de un sistema más amplio de educación nacional orientado desde el Estado, para aquellas poblaciones que poseen "una cultura, una lengua, unas tradiciones y unos fueros propios y autóctonos" [...]. En este sentido, nuestro planteamiento es que el multiculturalismo expresa un nuevo modo de enunciación, propio de la renovación en los aparatos de dominación, que no abandona su matriz colonial (p. 16).

Con respecto a lo anterior, la pregunta que surge frente a la Universidad Autonómica Indígena Intercultural (Uaiin) es: ¿no está respondiendo esta Institución a los cánones colonialistas de la educación intercultural, para la reproducción desde adentro de formas de dominación y exclusión racial y de género? Para que la Uaiin sea reconocida como institución de formación profesional, debe ser avalada y reconocida por el Ministerio de Educación, tras aprobar su visión política frente al proyecto político nacional. En este sentido, ¿el movimiento indígena no estaría cediendo su autonomía política para ser asimilado dentro del Estado, mediante programas de formación "interculturales y propios"?

Estas mujeres han hecho relecturas y críticas de los modelos sociales y escolares impuestos. A su vez, desde sus experiencias personales, reelaboran posiciones políticas y escolares que señalan sus necesidades étnicas, de clase y género. Evocan y reafirman la lucha ancestral de las mujeres a lo largo de la historia de la lucha indígena, como víctimas de la violencia histórica y reconocen, como parte de esta herencia misógina occidental, la violencia que recae sobre ellas al interior de sus familias. Por lo mismo, se han valido de su capital simbólico para posicionarse políticamente dentro del movimiento indígena. 
Para ello, han articulado elementos del campo jurídico y político de sociedades con herencia europea con las concepciones sobre la vida indígena y han asumido, en sí mismas, parte de la reproducción del universo femenino, lo cual ha generado mayor impacto de la difusión y respuesta de la comunidad nacional e internacional sobre las problemáticas de pervivencia de los pueblos indígenas.

\section{Referencias bibliográficas}

Bourdieu, P. (1997). Razones prácticas. Sobre la teoría de la acción. Barcelona: Anagrama.

Bourdieu, P. (2001). El campo político. La Paz: Plural editores.

Bourdieu, P., y Passeron, J. (2001). La reproducción: elementos para una teoría del sistema de enseñanza. Madrid: Popular.

Bourgois, P. (1996). In Search of Respect. Selling Crack in el Barrio. Nueva York: Cambridge University Press.

Encrevé, P., y Lagrave, R. M. (comps.) (2005). Trabajar con Bourdieu. Bogotá: Universidad Externado de Colombia.

Gil Roldan, Á. M. (2005). Tejiendo la vida universitaria en la capital: nuevos dilemas de la mujer indígena contemporánea. Bogotá: Universidad de los Andes.

Keck, M y Sikkin, K (2001). Activistas sin fronteras. Redes de defensa en política internacional. México D.F: Siglo veintiuno editores.

Kervran, D. (2010). Transformaciones de las solidaridades transnaciones: de las redes militantes hacia los campos globalizados. El caso de la defensa de las poblaciones indígenas. En R. Brett, y A. Santamaría (Comps.). Jano y las caras opuestas de los derecho humanos de los pueblos indígenas (pp. 27 - 39) Editorial Universidad del Rosario - CEPI. Bogotá.

Lumby, J. y Coleman, M. (2007). Leadership and diversity. Challenging theory and practice in education. Londres: SAGE.

Marcus, G. (2001). Etnografía en/del sistema mundo. El surgimiento de la etnografía multilocal. Alteridades, 11 (22), 111-127.

Montané, A., y Pessoa, M. E. (comps.). (2013). Mujeres y educación superior. Joao Pessoa: Universidade Federal de Paraíba.

Morales, P. (2011). Los idiomas de la reetnización. Corpus Christi y pagamentos entre los indígenas kankuamos en la Sierra Nevada de Santa Marta. Bogotá: Universidad Nacional de Colombia. 
Organización Indígena Kankuama [OIK]. (2009). Hoja de cruz. Memoria bistórica del conflicto armado en el pueblo indigena Kankuamo. 1985-2008. Valledupar: Kuino.

Pinto, L. (2002). Pierre Bourdieu y la teoría del mundo social. México D. F.: Siglo XXI.

Pratt-Clarke, M. (2013). A Radical Reconstruction of Resistance Strategies: Black Girls and Black Women Reclaiming Our Power Using Transdisciplinary Applied Social Justice, Ma’ta and Rites of Passage. Springer Science, 17 (1), 99-114.

Pumarejo, A., y Morales, P. (2003). La recuperación de la memoria bistórica de los kankuamos: un llamado de los antiguos. Siglo XX-XVII. Bogotá: Encuentros, Universidad Nacional de Colombia.

Quijano, A (2000). Colonialidad del poder, eurocentrismo y América Latina. En E. Langer (ed.), La colonialidad del saber: eurocentrismo y ciencias sociales. Perspectivas Latinoamericanas. (pp. 122-151). Buenos Aires. Clacso.

Rojas, A., y Castillo, E. (2007). Multiculturalismo y políticas educativas en Colombia. ¿Interculturalizar la educación? Revista Educación y pedagogía, XIX (48), 11- 24.

Santamaría, Á. (2008). Redes transnacionales de la diplomacia indígena: un estudio a partir del caso colombiano. Bogotá: Universidad del Rosario.

Santamaría, A. (2013). Eclosiones identitarias. Interseccionalidad y feminismo(s) en jaque. En Identidades políticas porosas. Estudios sobre las reivindicaciones sociales nacionales y transnacionales. Bogotá: Universidad del Rosario.

Santamaría, A. (2014). Etnicidad, género y educación superior. Trayectorias de dos mujeres arhuacas. Presentado en el coloquio de Universidad de Salta en Argentina patrocinado por UNTREF y UNESCO, abril de 2014.

Segato, R. (2010). Los causes profundos de la raza latinoamericana: una relectura del mestizaje. Crítica y Emancipación, (3), 11-44.

Tarrow, S. (2004). Elpoder en movimiento. Los movimientos sociales, la acción colectiva y la politica. Madrid: Alianza. 